\title{
A novel method for co-culture with Müller cells and microglia in rat retina in vitro
}

\author{
LI LI, CHEN QU and FANG WANG
}

Department of Ophthalmology, Shanghai Tenth People's Hospital Affiliated to Tongji University, Shanghai 200072, P.R. China

Received April 8, 2014; Accepted August 9, 2014

DOI: $10.3892 /$ br. 2014.370

\begin{abstract}
Microglia and Müller cells are glial cells of the retina and constitute a functional link between neurons and vessels. The aim of the present study was to introduce a novel method of co-culture with Müller cells and microglia in rat retina. A camera was used to analyze all the cell changes. Immunofluorescence staining of glutamine synthetase and OX-42 were used for the identification of Müller cells and microglial, respectively. On day 1 , all the cell types from the retina were round or oval and floating in the medium. On the following days, microglial cells were adherent and proliferated. Müller cells stretched and quickly proliferated. On days 12-15, microglial cells were floating in the medium. Following agitation, microglial cells became quickly detached from the flask walls, whereas Müller cells remained adherent. In conclusion, agitation is an effective way to separate microglial cells from Müller cells. The time of detachment and the speed of agitation are essential. Co-culture with Müller cells and microglia in the retina is economical and useful for future methods in microglia and Müller cell research.
\end{abstract}

\section{Introduction}

Microglia and Müller cells are glial cells of the retina and constitute a functional link between neurons and vessels $(1,2)$. Microglia cells are derived from myeloid cell lineage, which is a type of macrophage. Microglia adapt to control neuronal growth in the retina and they are active phagocytes, clearing dying photoreceptor cells. Responses to photoreceptor degeneration and retinal injury induce microglial migration and accumulation. However, excessive activation and proliferation of microglial cells can lead to neuronal degeneration and necrosis (3-7). Müller cells support blood-retinal barrier integrity, remove metabolic waste and maintain the balance of the

Correspondence to: Dr Fang Wang, Department of Ophthalmology, Shanghai Tenth People's Hospital Affiliated to Tongji University, 301 Middle Yanchang Road, Shanghai 200072, P.R. China E-mail: wangfang201466@126.com

Key words: Müller cells, microglial cells, agitating, glutamine synthetase, OX-42 retinal extracellular environment (ions, water and $\mathrm{pH}$ ). Active Müller cells in pathological conditions can lead to retinal degeneration and edema formation $(1,8,9)$.

A previous study found that during retinal degeneration, the functional interactions between Müller cells and microglia may be bidirectional and regulate photoreceptor cells survival (9). Currently, there are increasing studies focusing on the interaction between retinal microglial cells and Müller cells (9). In the present study, a novel method will be introduced for the co-culture of Müller cells and microglia in rat retina.

\section{Materials and methods}

Cell culture. The eyeballs of newborn (0-3 days) Sprague-Dawley rats (SLAC Laboratory Animal Co., Ltd, Shanghai, China) were opened to obtain the retina. The retinal tissue was washed in cold Hanks' solution (Amresco LLC, Solon, OH, USA) and separated into 1-3-mm pieces. The mixture was transferred into sterile centrifuge tubes and centrifuged (1,100 x g, $10 \mathrm{~min})$. The supernatant was discarded and subsequently, a total of $0.125 \%$ trypsin (Amresco LLC) was added to digest. The mixture was incubated at $37^{\circ} \mathrm{C}$ for $15 \mathrm{~min}$. Following this, Dulbecco's modified Eagle's medium/F12 medium (Gibco, Invitrogen, Carlsbad, CA, USA) supplemented with $2 \mathrm{mmol} / 1$ glutamine, $100 \mathrm{U} / \mathrm{ml}$ penicillin, $100 \mu \mathrm{g} / \mathrm{ml}$ streptomycin and $10 \%$ fetal bovine serum (Sijiqing, Shanghai, China) was added to terminate digestion. The digests were filtered using a 200-mesh nylon sieve and centrifuged (1,100 x g, $10 \mathrm{~min})$. The supernatant was discarded. The cell suspension was cultured in $\mathrm{T} 75$ culture flasks at $37^{\circ} \mathrm{C}$ in humidified air containing $5 \% \mathrm{CO}_{2}$, in the incubator (Thermo, Germany).

On day 3 , the medium in the flasks was collected and centrifuged $(1,100 \mathrm{x} \mathrm{g}, 10 \mathrm{~min})$. The supernatant was discarded and new medium was added. The cell suspension was cultured for $2 \mathrm{~h}$ in the T75 flasks pre-coated with $12.5 \mathrm{mg} / \mathrm{l}$ Poly-L-Lysine (PLL) (Sigma-Aldrich, Hong Kong, SAR, China). There were more Müller cells in the original flasks, while more microglial cells grew in the pre-coated PLL flasks. All the flasks were placed in the incubator at $37^{\circ} \mathrm{C}$ in an atmosphere of $5 \% \mathrm{CO}_{2}$. The medium of the Müller-cell flasks was renewed on the next day. When the Müller cells were confluent, and therefore covering the flask walls, they were digested with $0.25 \%$ trypsin again for subculture. The medium of the microglial-cell flasks was renewed on day 5. Subsequently, half of the medium was changed every week. On days 12-15, when the cells were 

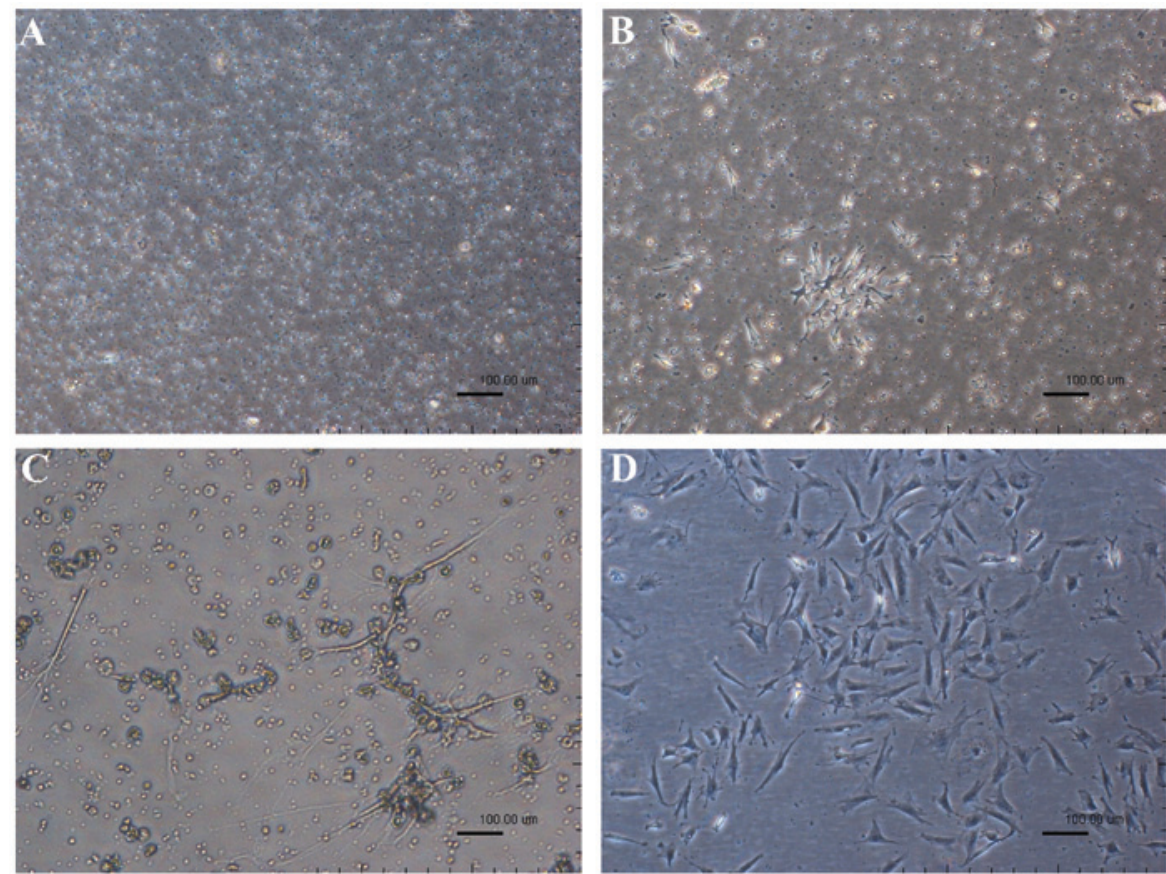

Figure 1. (A) On day 1, all types of cells from the retina were round or oval and floating in the medium. (B) On the following days, microglial cells began to adhere and proliferate. (C) Microglial began to stretch into amoeba shapes. (D) Müller cells stretched and quickly proliferated.
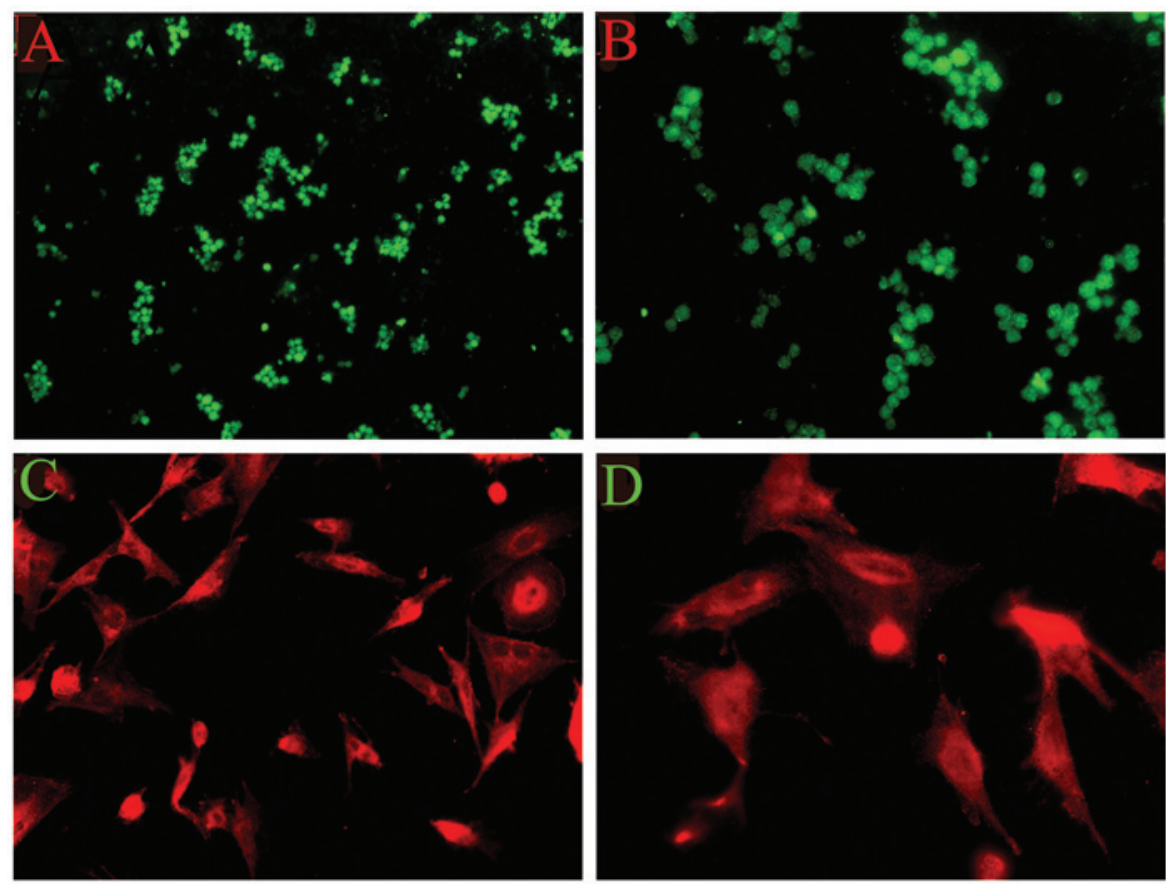

Figure 2. (A and B) Microglia were labeled by OX-42. (C and D) Müller cells were labeled by glutamine synthetase.

almost confluent $(\sim 80-90 \%)$, the flasks were agitated at $37^{\circ} \mathrm{C}$, $110 \mathrm{x} \mathrm{g}$ for $1 \mathrm{~h}$. The suspension was collected and centrifuged at $1,100 \mathrm{x} \mathrm{g}$ for $10 \mathrm{~min}$. The supernatant was discarded. The new flasks, without pre-coated PLL, were used for microglial cell subculture. The camera (Canon, Japan) was used to observe the cell change on the various days in the flasks.

Immunofluorescence. Immunofluorescence was carried out to identify microglia and Müller cells. Microglia were labeled as described previously by Saura (10). The Müller cells were labeled by glutamine synthetase (GS) (11).

Microglia identification. The cells were washed by phosphate-buffered saline (PBS) (137 mM NaCl, $2 \mathrm{mM} \mathrm{KCl}, 8 \mathrm{mM}$ $\mathrm{Na}_{2} \mathrm{HPO}_{4}$ and $\left.1 \mathrm{mM} \mathrm{KH} \mathrm{PO}_{4}\right)$ three times and centrifuged $(1,100 \times \mathrm{g}, 10 \mathrm{~min}$ ), and subsequently maintained in PBS (Amresco LLS). The cell concentration was adjusted to $1 \times 10^{6}$ cells $/ \mathrm{ml}$. The Cytospin ${ }^{\mathrm{TM}} 4$ Cytocentrifuge (Shandon, Shanghai, China) 
(900 x g, 10 min) was used for smearing the cells. The cells were fixed with $4 \%$ paraformaldehyde at room temperature (RT) for $10 \mathrm{~min}$, followed by incubation with $0.05 \%$ Triton X-100 at $37^{\circ} \mathrm{C}$ for $10 \mathrm{~min}$ to increase cell membrane permeability. The cells were washed three times (10 min/wash) with PBS, and incubated in $10 \%$ goat serum albumin (Invitrogen, Hong kong, USA) for $30 \mathrm{~min}$ to block non-specific binding sites. The cells were subsequently incubated overnight at $4^{\circ} \mathrm{C}$, with mouse anti-rat OX-42 antibody (1:200; Millipore, Billerica, MA, USA). Following the overnight incubation with the primary antibodies, the cells were washed three times (10 min/wash) with PBS and were incubated with secondary anti-mouse immunoglobulin $\mathrm{G}$ (IgG)-fluorescein isothiocyanate antibodies (1:400; Invitrogen) at $37^{\circ} \mathrm{C}$ in the dark for $1 \mathrm{~h}$. Following three washes with PBS, the cells on the coverslips were mounted on glass slides with HistoMount $^{\mathrm{TM}}$ (Invitrogen). The cells were viewed under an Axio microscope (Zeiss, Göttingen, Germany) and images were acquired with a digital camera (Zeiss).

Müller cell identification. The cells on the coverslips were incubated at $37^{\circ} \mathrm{C}$ for one day and subsequently washed three times (10 min/wash) with PBS. The cells were fixed with $4 \%$ paraformaldehyde at RT for $10 \mathrm{~min}$ and incubated with $0.3 \%$ Triton $\mathrm{X}-100$ at $37^{\circ} \mathrm{C}$ for $10 \mathrm{~min}$. Subsequently, the cells were washed three times (10 min/wash) with PBS and incubated in $10 \%$ goat serum albumin for $30 \mathrm{~min}$, prior to incubating overnight at $4^{\circ} \mathrm{C}$ with rabbit anti-rat GS antibody $(1: 5,000$; Abcam, Cambridge, MA, USA). On the following day, the cells were washed three times (10 min/wash) with PBS and were incubated with secondary anti-rabbit IgG-Cy3 antibodies (1:200; BioLegend, Inc., San Diego, CA, USA) at $37^{\circ} \mathrm{C}$ in the dark for $1 \mathrm{~h}$. Following three washes with PBS, the cells on the coverslips were mounted on glass slides with HistoMount ${ }^{\mathrm{TM}}$. The cells were viewed under an Axio microscope and images were acquired with a digital camera (Zeiss).

\section{Results}

Co-culture of microglia and Müller cells. On day 1, all the cell types from the retina were round or oval, and were floating in the medium (Fig. 1A). As the adherent speed of Müller cells was quicker compared to the other types of cells, they were adherent to the flask walls after several hours. On the following days, microglial cells began to become adherent and proliferated (Fig. 1B). Müller cells were observed to be stretching and proliferating quickly (Fig. 1D). On days 12-15, when increasing numbers of round cells were floating in the medium, they were almost all microglial cells, and therefore, the flask was agitated to isolate the microglial cells for subculture. Microglial cells quickly adhered to the walls following agitation, and they began to stretch into amoeba shapes (Fig. 1C).

Microglia were labeled by OX-42 (Fig. 2A and B) and Müller cells were labeled by GS (Fig. 2C and D).

\section{Discussion}

A previous study noted that caution must be applied when claiming pure Müller cell cultures due to the presence of microglia in the cultures (10). However, in our previous study, we showed that numerous types of cells had to sit on top of the Müller cell monolayer, which were mainly microglial cells after 24-48 $\mathrm{h}$ (10). To the best of our knowledge, this is the first study to demonstrate agitation as an effective technique for detaching microglial cells from Muller cells.

Similar to the central nervous system, the retina has a number of mechanisms that respond effectively to danger, control inflammation and resume normal function without an exhaustive healing response. This requires a fine balance between the control of the resident myeloid cell population and neurons, and its receptor that is expressed on macrophages, such as microglia and Müller cells. Retinal degeneration and edema induce microglia from a resting state to activation state. Furthermore, microglia-derived factors influence the production of secondary factors in Müller cells. All these together generate a microglia-Müller glia cell network. The gila-gila network may be a novel therapeutic target for neurodisease. Further investigation is necessary to reveal the association between microglia and Müller cells during retinal disease (6,12-16).

Co-culture with Müller cells and microglia in the retina is economical and therefore, is useful as a future method for microglia and Müller cells research.

\section{References}

1. Reichenbach A, Wurm A, Pannicke T, Iandiev I, Wiedemann P and Bringmann A: Müller cells as players in retinal degeneration and edema. Graefes Arch Clin Exp Ophthalmol 245: 627-636, 2007.

2. Tezel G and Wax MB: The immune system and glaucoma. Curr Opin Ophthalmol 15: 80-84, 2004.

3. Forrester JV and McMenamin P: Immunopathogenic mechanisms in intraocular inflammation. Chem Immunol 73: 159-185, 1999.

4. Egensperger R, Maslim J, Bisti S, Holländer H and Stone J: Fate of DNA from retinal cells dying during development: uptake by microglia and macroglia (Müller cells). Brain Res Dev Brain Res 97: 1-8, 1996.

5. Roque RS, Imperial CJ and Caldwell RB: Microglial cells invade the outer retina as photoreceptors degenerate in Royal College of Surgeons rats. Invest Ophthalmol Vis Sci 37: 196-203, 1996.

6. Dick AD, Carter D, Robertson M, et al: Control of myeloid activity during retinal inflammation. J Leukoc Biol 74: 161-166, 2003.

7. Bringmann A, Pannicke T, Grosche J, et al: Müller cells in the healthy and diseased retina. Prog Retin Eye Res 25: 397-424, 2006.

8. Walsh N, Valter K and Stone J: Cellular and subcellular patterns of expression of bFGF and CNTF in the normal and light stressed adult rat retina. Exp Eye Res 72: 495-501, 2001.

9. Harada T, Harada C, Kohsaka S, et al: Microglia-Müller glia cell interactions control neurotrophic factor production during light-induced retinal degeneration. J Neurosci 22: 9228-9236, 2002.

10. Saura J: Microglial cells in astroglial cultures: a cautionary note. J Neuroinflammation 4: 26, 2007.

11. Chen $\mathrm{H}$ and Weber AJ: Expression of glial fibrillary acidic protein and glutamine synthetase by Müller cells after optic nerve damage and intravitreal application of brain-derived neurotrophic factor. Glia 38: 115-125, 2002.

12. Park LC, Zhang $\mathrm{H}$ and Gibson GE: Co-culture with astrocytes or microglia protects metabolically impaired neurons. Mech Ageing Dev 123: 21-27, 2001.

13. Zack DJ: Neurotrophic rescue of photoreceptors: are Müller cells the mediators of survival? Neuron 26: 285-286, 2000.

14. Tynan RJ, Naicker S, Hinwood M, et al: Chronic stress alters the density and morphology of microglia in a subset of stress-responsive brain regions. Brain Behav Immun 24: 1058-1068, 2010.

15. Tackenberg MA, Tucker BA, Swift JS, Jiang C, Redenti S, Greenberg KP, Flannery JG, Reichenbach A and Young MJ: Müller cell activation, proliferation and migration following laser injury. Mol Vis 15: 1886-1896, 2009.

16. Yu J, Huang X, Wu Q, Wang J, Yu X and Zhao P: Effect of A2A receptor antagonist (SCH 442416) on the mRNA expression of glutamate aspartate transporter and glutamine synthetase in rat retinal Müller cells under hypoxic conditions in vitro. Exp Ther Med 3: 803-806, 2012. 